\title{
Pressure changes under the ischial tuberosities of seated individuals during sacral nerve root stimulation
}

\begin{abstract}
Liang Qin Liu, MBBS; ${ }^{1-2}$ Graham P. Nicholson, PhD; ${ }^{3}$ Sarah L. Knight, PhD; ${ }^{1-2}$ Ramesh Chelvarajah, MRCS; $^{1}$ Angela Gall, MRCP; ${ }^{4}$ Fred R. I. Middleton, FRCP; ${ }^{4}$ Martin W. Ferguson-Pell, PhD; ${ }^{3}$ Michael D. Craggs, PhD; ${ }^{1-2 *}$ ${ }^{1}$ Spinal Research Centre, Royal National Orthopaedic Hospital (RNOH), Stanmore, United Kingdom; ${ }^{2}$ Institute of Urology, University College London, London, United Kingdom; ${ }^{3}$ Aspire Centre for Disability Sciences, University College London, London, United Kingdom; ${ }^{4}$ The London Spinal Cord Injuries Centre, RNOH, Stanmore, United Kingdom
\end{abstract}

\begin{abstract}
Neuromuscular stimulation via the sacral nerve roots is proposed for prevention of ischial pressure ulcers following a spinal cord injury (SCI). Acute effects of sacral functional magnetic stimulation (FMS) on seat interface pressure changes were investigated in five nondisabled volunteers. Similar effects were demonstrated with functional electrical stimulation in people with SCI who used a sacral anterior root stimulator implant. The results indicated that sacral nerve root stimulation, either by FMS or implanted electrical stimulation, induced gluteus maximus contraction and mild pelvic tilt sufficient for clinically significant reductions in ischial pressures during sitting.
\end{abstract}

Key words: functional electrical stimulation, functional magnetic stimulation, gluteal muscles, ischial pressure change, ischial tuberosity, pressure ulcer, sacral nerve root stimulation, seat interface pressure, spinal cord injury, wheelchair use.

\section{INTRODUCTION}

Pressure ulcers (PUs) are one of the most serious complications associated with spinal cord injury (SCI). PUs account for approximately 25 percent of the overall treatment costs for people with SCI, at an estimated annual cost of $\$ 1.2$ billion to the U.S. healthcare system [1]. In the United Kingdom, the total annual cost of PU care has been reported up to $£ 2.1$ billion [2]. Approximately 25 to 85 percent of patients have PUs during their lifetime following SCI [3-5]. The ischial tuberosity (IT) is one of the most common sites for PU development in people with SCI who use wheelchairs [6]. An estimated 36 to 50 percent of PU incidence results from sitting in a wheelchair [7].

Many intrinsic and extrinsic factors contribute to PU development. However, the main factor associated with PUs in people with SCI who use wheelchairs is prolonged localized pressure on the atrophied gluteal muscles that leads to local tissue ischemia [8-11]. Lack of sensation below the level of injury leads to insensitivity to the ischemia and makes wheelchair users with SCI particularly at risk for PU development. The excessive external pressure on the capillaries causes decreased blood supply and oxygen delivery, which can trigger hypoxia in local tissues; furthermore, occluded lymphatic drainage can damage deeper tissues [7].

\footnotetext{
Abbreviations: ASCII = American Standard Code for Information Interchange, FES = functional electrical stimulation, FMS = functional magnetic stimulation, IT = ischial tuberosity, $\mathrm{PU}=$ pressure ulcer, $\mathrm{S}=$ sacral, SARS $=$ sacral anterior root stimulator, SCI = spinal cord injury, SEM = standard error of measurement.

*Address all correspondence to Professor Michael Craggs; Spinal Research Centre, Royal National Orthopaedic Hospital, Stanmore, Middlesex HA7 4LP, United Kingdom; +44-20-8909-5343; fax: +44-20-8909-5343.

Email: michael.craggs@ucl.ac.uk

DOI: 10.1682/JRRD.2005.04.0078
} 
Once formed, PUs are costly, difficult to fully repair, and increase the risk of ulcer recurrence, particularly in the SCI population [12-15]. Thus far, approaches to the prevention of PUs in people with SCI have generally focused on education and device selection. A combination of specialized cushions for reducing pressure and pressure-relief movements, in which the patient performs "push-ups" or "leans forward," is considered the best option for PU prevention in people with SCI [16-19]. However, pressurerelief movements require good upper-limb strength and continued motivation, which are not always present in people with high-level lesions. Although many kinds of wheelchair cushions have been evaluated for their effectiveness in reducing seat interface pressures [18,20-21], these studies generally concluded that seat cushions alone do not adequately relieve pressure during continuous sitting. The incidence of PUs remains unacceptably high [13-15,22]. In view of the limitations of current preventive methods, alternative means of PU prevention need to be investigated.

Levine et al. investigated the dynamic changes in seat interface pressure using surface functional electrical stimulation (FES) of the gluteus maximus [23-25]. Interestingly, their results indicated that FES can change the shape of loaded buttocks, which significantly reduces pressure under the ITs and redistributes it over other parts of the seat interface. However, in these studies, the muscles were stimulated in a cumbersome manner by repeated application of large electrodes to the buttocks. The long-term practicality of and patient compliance with this technique are problematic. Most recently, Bogie et al. used an implanted muscular electrical stimulation system to enable SCI patients to stand. They found that electrical stimulation of the gluteus maximus decreased pressure under the ischial region after an 8-week FES exercise program $[10,26]$. Lippert-Gruner presented a case report on use of an anal probe for stimulating gluteal muscles and hence healing gluteal PUs [27]. An implanted sacral FES device may be a more practical solution, especially if its utility can be demonstrated noninvasively. For example, functional magnetic stimulation (FMS) of the sacral nerve roots can effectively and noninvasively contract gluteal and pelvic-floor muscles [28]. Moreover, for chronic stimulation of the gluteal muscles, electrical stimulation of the sacral nerve roots through implanted electrodes may more effectively build muscle bulk, reduce seating pressure, and improve local skin circulation, thus preventing ischial PUs in people with SCI who use wheelchairs.

In this study, we aimed to-

1. Investigate the acute effects of sacral FMS on seat interface pressure changes in nondisabled volunteers and demonstrate the utility of FMS as an assessment tool.

2. Use a FineTech Brindley (Herts, England) sacral anterior root stimulator (SARS) implant to show that FES has similar effects in people with SCI.

\section{METHODS}

\section{Subjects}

The study protocol was approved by the local ethics committee. All participants gave their informed consent. For the sacral FMS study, we excluded individuals who were pregnant or using a cardiac pacemaker, which are contraindications to magnetic stimulation. Five nondisabled males, aged 29 to 60 years, participated.

For the sacral FES study, we included individuals 18 to 65 years old who had suprasacral SCI (complete/ incomplete) and a SARS implant and excluded individuals with current PUs over the gluteal region or with a history of severe autonomic dysreflexia. Four males and one female with SCI and a SARS implant participated (aged 34 to 62 years, level of injury from third thoracic to eleventh thoracic vertebrae complete, and duration of injury from 9 to 24 years) (Table $\mathbf{1}$ ).

Table 1.

Baseline characteristics of five participants with spinal cord injury (SCI) and sacral anterior root stimulator implant.

\begin{tabular}{ccclccc}
\hline Subject & Age (yr) & Sex & Level of Injury & Year of SCI & History of Ischial PUs & Roots Implanted \\
\hline 1 & 34 & F & T7/8 complete & 1992 & No & S2, S3, S4 \\
2 & 41 & M & T4/5 complete & 1980 & Stage I PU (right) & S2, S3, S4 \\
3 & 38 & M & T4 complete & 1995 & No & S2, S3, S4 \\
4 & 50 & M & T3 complete & 1995 & State II PU & S2, S3, S4 \\
5 & 62 & M & T10/11 complete & 1982 & Stage I PU (left) & S2, S3, S4 \\
\hline
\end{tabular}




\section{Phantom Study}

Before the sacral FMS study, we carried out a phantom study to identify possible magnetic stimulation interference on the interface pressure mapping and acquisition hardware [29]. We used a repetitive magnetic stimulator (MagPro, Dantec Dynamics A/S, Skovlunde, Denmark) with a large circular coil (120 mm diameter) to apply magnetic stimulation to a cushion-loading indentor [30-31] that was loading a cushion and pressure-mapping the effects of the magnetic pulses on the interface pressure mapping system $(36 \times 36$ cells at $10 \mathrm{~mm}$ pitch, XSENSOR Technology Corporation, Calgary, Alberta, Canada). The magnetic stimulating coil was applied against the "sacrum area" of the cushion-loading indentor and was energized at single pulse frequencies of 5 to $20 \mathrm{~Hz}$ and an intensity of 30 to 90 percent of maximum stimulator output during mapping of interface pressure. We compared the interface pressure measurements with the stimulator off and on by converting the data to American Standard Code for Information Interchange (ASCII) format. Interface pressures did not change before, during, and after stimulation. In other words, no magnetic stimulation artifact was detected on the interface pressure mapping.

\section{Ischial Pressure Measurement}

Each participant sat in a wheelchair with fitted arm and foot rests. Ischial pressures were measured with an interface pressure-mapping system $(36 \times 36$ cells at $10 \mathrm{~mm}$ pitch, XSENSOR Technology Corporation, Calgary, Alberta, Canada). The seat pressure mat was placed between the participant and the standard foam cushion (high-resilience foam, density $45 \mathrm{~kg} / \mathrm{m}^{3}$ ). Before the study began, the seat pressure mat was calibrated according to the manufacturer's instructions. An initial data set was recorded once the subjects were stabilized in a standard sitting position defined as backrest-to-seat angle of at least $80^{\circ}$ and footrest adjustment such that the thighs were parallel to the seat. Seat pressures were recorded before, during, and after stimulations. The sample rate of pressure mapping was $7 \mathrm{~Hz}$ frame/second. Real-time two-dimensional images of pressure distribution at the seat interface were produced with the graphical display software provided with the pressure mapping system and were saved in a personal computer.

All data were then converted to ASCII format. Interface pressure readings were peak pressure, defined as the highest individual sensor value under the ITs, and gradient at peak pressure, defined as the average difference among the highest sensor value and the values from the surrounding eight sensors. We analyzed pressure measurements by comparing the peak pressure and gradient at peak pressure. We used two-tailed paired $t$-tests with a 95 percent confidence interval to compare the pressure parameters before and during stimulations. Statistical significance was defined as $\alpha=0.05$.

\section{Sacral Functional Magnetic Stimulation}

FMS was delivered by placement of a repetitive magnetic stimulator (MagPro, Dantec Dynamics A/S, Skovlunde, Denmark) with a large circular coil (120 mm diameter) over the sacrum area of the five nondisabled participants. To obtain smooth tetanic contraction of the gluteal muscles, we used stimulation frequencies ranging from 15 to 25 pps at 50 to 70 percent intensity for 2 seconds.

The optimal coil position for sacral nerve root stimulation was determined by mapping of the gluteal muscle response [28]. The coil was placed over various points of a grid pattern that ranged from the iliac crest to $10 \mathrm{~cm}$ below and $8 \mathrm{~cm}$ on either side of midline of the iliac crest.

\section{Sacral Functional Electrical Stimulation via Sacral Anterior Root Stimulator Implant}

Electrical stimulation was applied bilaterally via the participants' implanted SARS (currently used for bladder emptying [32-33]). Before the experiment, the participants were asked to empty their bladders and bowels. Then, only the second sacral (S2) nerve root was stimulated. To obtain a smooth tetanic contraction of the gluteal muscles, we used a stimulation frequency of $20 \mathrm{pps}$ at a pulse width that varied from 8 to 800 seconds and an amplitude of " 1 " for 10 seconds.

\section{RESULTS}

\section{Sacral Functional Magnetic Stimulation}

All five nondisabled participants tolerated FMS well and experienced no adverse effects. We determined peak pressure values under the ITs for each of the six frames within a data set and averaged the six frames. Figure 1 shows bilateral peak pressure traces before, during, and after stimulation (Figure 1(b)) when the coil was placed at the midline of S2 level (Figure 1(a)). The difference between resting and stimulated pressures at the ITs was statistically significant. The results for individual participants are summarized in Table 2. 
With optimal stimulation, the five nondisabled participants obtained an average 20 percent reduction of peak pressure and 23 percent reduction of gradient at peak pressure. Peak pressures decreased during FMS as compared

(a)
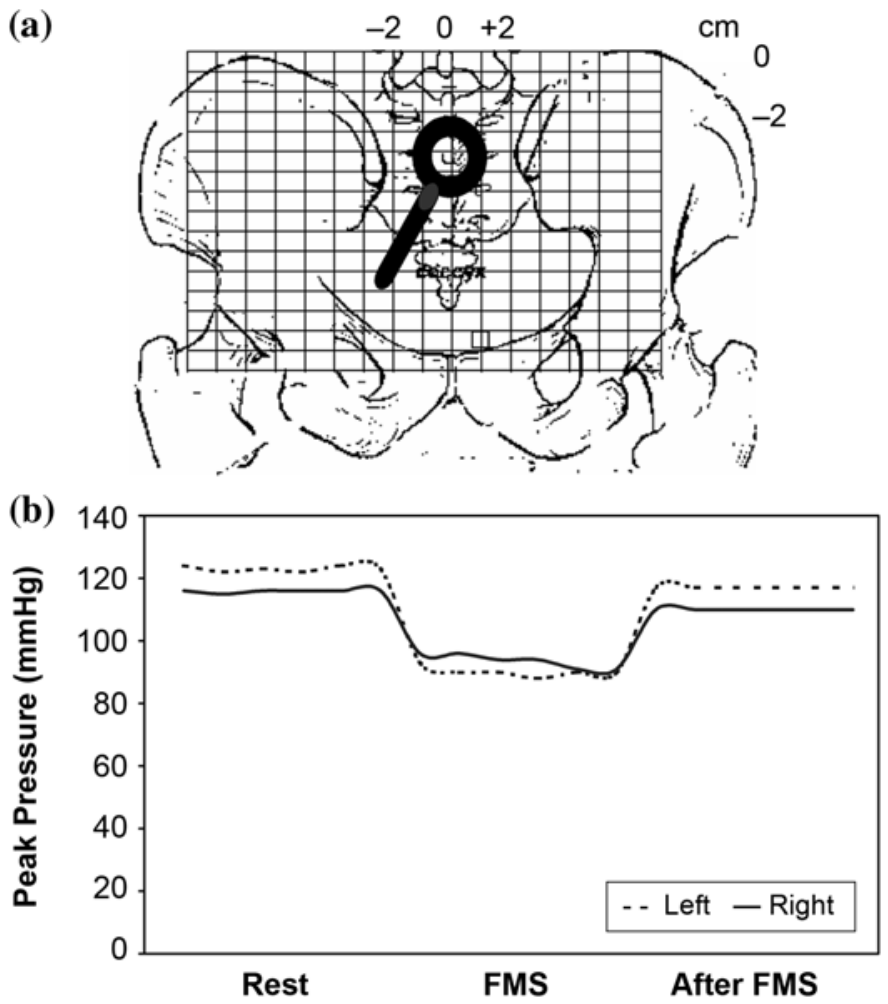

Figure 1.

(a) Coil placed at midline of second sacral foramen level over a pelvis superimposed by a grid. (b) Bilateral peak pressure at rest, during functional magnetic stimulation (FMS), and after FMS for one nondisabled participant with coil optimally placed as shown. with baseline (mean \pm standard error of measurement $[\mathrm{SEM}]=123.6 \mathrm{mmHg} \pm 8.3[16.3 \mathrm{kPa} \pm 1.1]$ at rest vs $98.7 \mathrm{mmHg} \pm 8.2[13.1 \mathrm{kPa} \pm 1.1]$ during stimulation, $p=$ 0.03, paired two-tailed $t$-test) (Figure 2); similarly, the gradient at peak pressure decreased during FMS as compared with baseline (mean \pm SEM $=35.0 \mathrm{mmHg} / \mathrm{cm} \pm 7.1$ $[4.7 \mathrm{kPa} / \mathrm{cm} \pm 0.9]$ at rest vs $27.4 \mathrm{mmHg} / \mathrm{cm} \pm 6.6$ [3.6 kPa/cm \pm 0.9$]$ during stimulation, $p<0.01$, paired two-tailed $t$-test). The response was optimal with the coil at S2 level (about $6 \mathrm{~cm}$ below iliac crest) as shown in Figure 3. For bilateral pressure decrease, the optimal coil position was at the midline; for ipsilateral response, the optimal position was at 2 to $4 \mathrm{~cm}$ lateral to midline. Increased FMS intensity was associated with greater reduction in peak pressure, as would be expected.

\section{Sacral Anterior Root Stimulator Implant}

All five participants with SCI completed the study and reported no muscular, skeletal, or bladder complications. Bilateral S2 stimulation caused palpable contraction of the gluteus maximus and mild hip and leg movements. We determined peak pressure and gradient at peak pressure under the ITs for each of the six frames within a data set and averaged the six frames. Initial data analysis showed no significant differences between left and right ischial pressure; therefore, bilateral values were averaged for each subject. The results for individual participants are summarized in Table 3.

Figure 4 shows typical seat interface pressure distribution before and during stimulation in one participant with SCI. With optimal stimulation, the five participants with SCI obtained an average 33 percent reduction of

Table 2.

Ischial tuberosity peak pressure and gradient at peak pressure before and during functional magnetic stimulation (FMS) in five nondisabled participants.

\begin{tabular}{|c|c|c|c|c|c|c|c|}
\hline \multirow[t]{2}{*}{ Subject } & \multicolumn{2}{|c|}{$\begin{array}{l}\text { Peak Pressure } \\
\text { (mmHg) }\end{array}$} & \multirow{2}{*}{$\begin{array}{l}\text { Peak Pressure } \\
\text { Drop (mmHg) }\end{array}$} & \multirow{2}{*}{$\begin{array}{l}\text { Peak Pressure } \\
\text { Change (\%) }\end{array}$} & \multicolumn{2}{|c|}{$\begin{array}{l}\text { Gradient at Peak Pressure } \\
(\mathbf{m m H g} / \mathbf{c m})\end{array}$} & \multirow{2}{*}{$\begin{array}{c}\text { Gradient at Peak } \\
\text { Pressure Drop } \\
\text { (mmHg/cm) }\end{array}$} \\
\hline & Before FMS & During FMS & & & Before FMS & During FMS & \\
\hline 1 & 116.3 & 112.0 & 4.3 & 3.4 & 37.0 & 24.0 & 13.0 \\
\hline 2 & 156.3 & 120.5 & 35.8 & 21.8 & 50.0 & 39.0 & 11.0 \\
\hline 3 & 110.3 & 77.3 & 33.0 & 30.0 & 23.0 & 16.0 & 7.0 \\
\hline 4 & 116.8 & 83.3 & 33.5 & 28.9 & 50.0 & 46.0 & 4.0 \\
\hline Mean \pm SEM & $123.6 \pm 8.3$ & $98.7 \pm 8.2^{*}$ & $24.8 \pm 6.14$ & $19.8 \pm 4.9$ & $35.0 \pm 7.1$ & $27.4 \pm 6.6^{\dagger}$ & $7.6 \pm 1.9$ \\
\hline $\begin{array}{l}{ }^{*} p<0.05 \\
{ }^{\dagger} p<0.01 \text { vs be }\end{array}$ & S. & & & & & & \\
\hline
\end{tabular}


peak pressure (mean \pm SEM $=148.6 \mathrm{mmHg} \pm 10.0$ $[19.8 \mathrm{kPa} \pm 1.3]$ at rest vs $99.8 \mathrm{mmHg} \pm 6.7[13.3 \mathrm{kPa} \pm$ $0.9]$ during stimulation, $p=0.002$, paired two-tailed $t$-test) (Figure 5) and 38 percent reduction of the gradient at peak pressure (mean $\pm \mathrm{SEM}=54.6 \mathrm{mmHg} / \mathrm{cm} \pm 8.8$ $[7.3 \mathrm{kPa} / \mathrm{cm} \pm 1.2]$ at rest vs $33.8 \mathrm{mmHg} / \mathrm{cm} \pm 7.8$ [4.5 $\mathrm{kPa} / \mathrm{cm} \pm 1.0]$ during stimulation, $p=0.03$, paired two-tailed $t$-test). Increased pulse width of sacral nerve root stimulation produced greater reduction in peak pressure; peak pressure stabilized after reaching maximum responses. Maximum reduction of peak pressure was achieved at a stimulation pulse width that varied from 64 to $600 \mathrm{~s}$ in the five participants with SCI. As a group, the five participants with SCI showed maximum reduction of peak pressure at a $256 \mathrm{~s}$ stimulation pulse width (Figure 6).

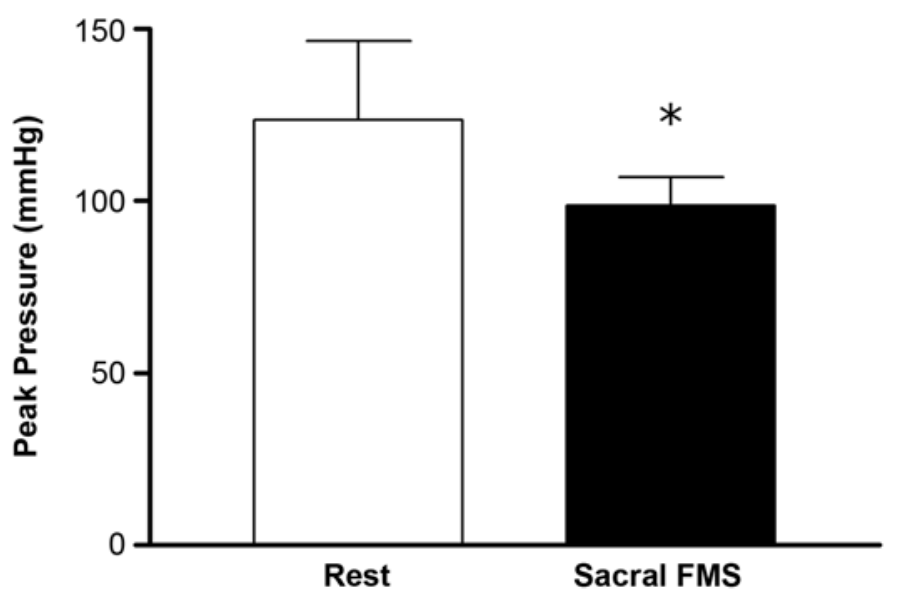

Figure 2.

Ischial tuberosity peak pressures before (rest) and during optimal sacral functional magnetic stimulation (FMS) in five nondisabled participants (mean \pm standard error of measurement $=123.6 \mathrm{mmHg} \pm$ 8.3 at rest vs $98.7 \mathrm{mmHg} \pm 8.2$ during FMS). ${ }^{*}$ Significant at $p=0.03$.

\section{DISCUSSION}

Our results demonstrate that S2 nerve root stimulation by FMS or an implanted electrical stimulator can induce gluteal muscle contraction sufficient for statistically and clinically significant ischial pressure reduction during sitting. In five nondisabled participants, maximum effects were obtained at approximately S2 foramen level with optimal magnetic stimulation; in five participants with SCI and a SARS implant, maximum reduction of peak pressure was obtained by S2 stimulation with a 64 to $600 \mathrm{~s}$ pulse width and 20 pps frequency.

S2 nerve root stimulation by FMS or an implanted electrical stimulator effectively induced gluteus maximus contraction and mild pelvic tilt and significantly reduced seating pressures. The peak pressure reductions in this study were similar to those obtained by Ferguson et al. [34] who studied electrical stimulation of quadriceps and by Burns and Betz [35] and Henderson et al. [36] who

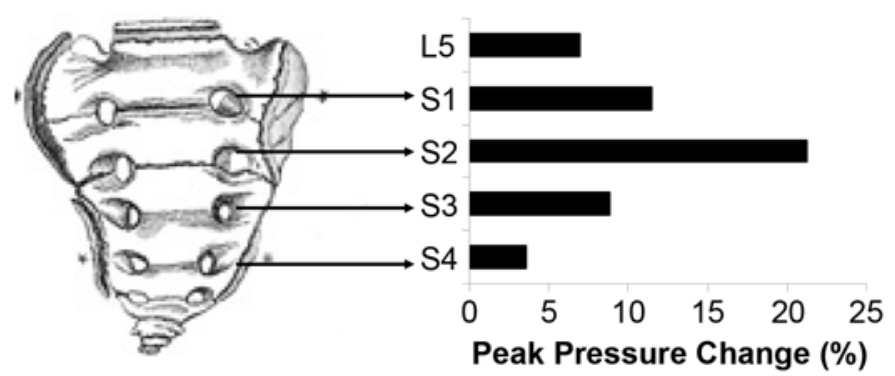

Figure 3.

Reduction in ischial tuberosity peak pressure during functional magnetic stimulation of five nondisabled participants at midline of different levels (L5-S4) below iliac crest. L = lumbar, $\mathrm{S}=$ sacral.

Table 3.

Ischial tuberosity peak pressure and gradient at peak pressure before and during sacral nerve root functional electrical stimulation (FES) in five participants with spinal cord injury and sacral anterior root stimulator implant.

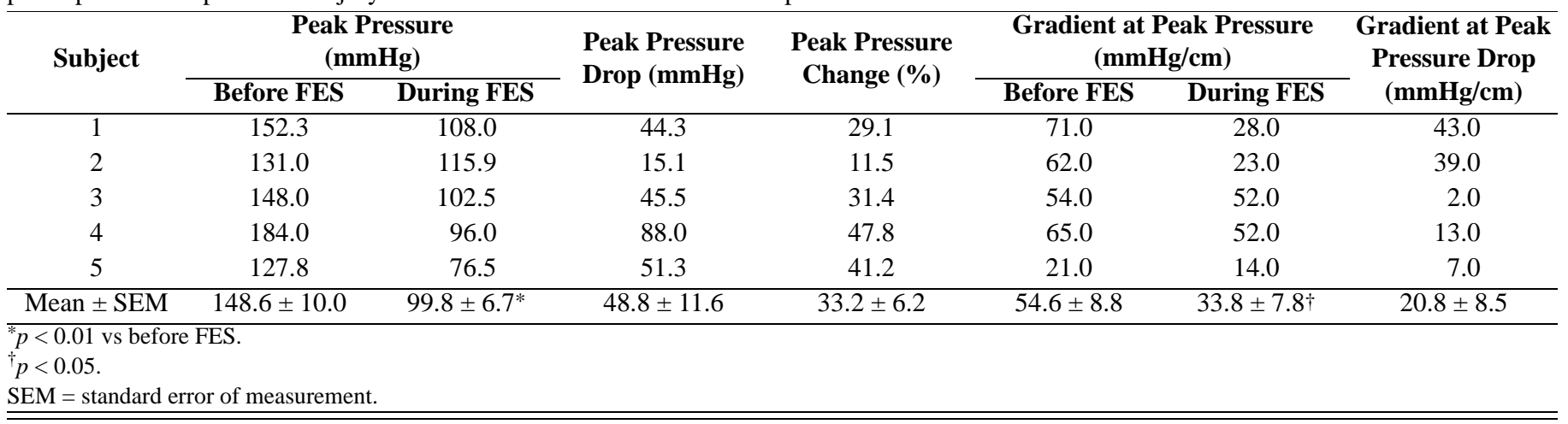




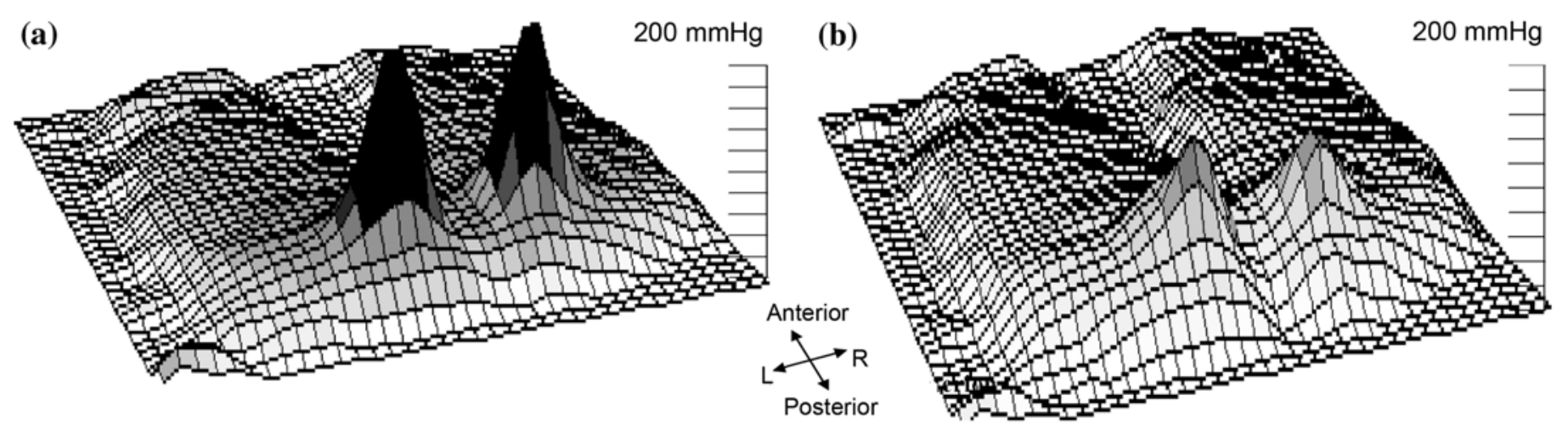

Figure 4.

Seat interface pressure distribution in one male patient with spinal cord injury (a) before and (b) during functional electrical stimulation of second sacral nerve root via a sacral anterior root stimulator implant. $\mathrm{L}=$ left, $\mathrm{R}=$ right.

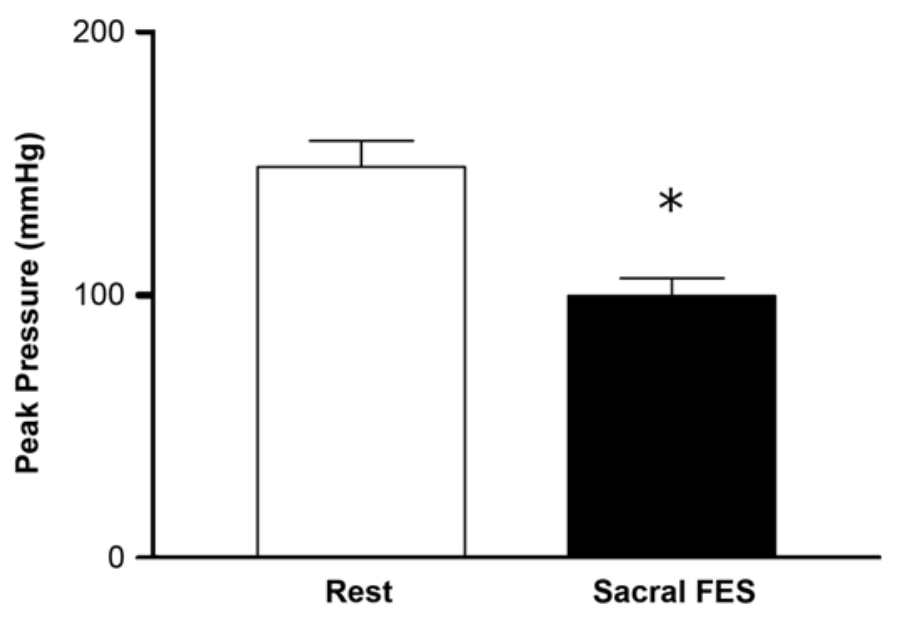

Figure 5.

Ischial tuberosity peak pressure before (rest) and during optimal sacral functional electrical stimulation (FES) in five participants with spinal cord injury and sacral anterior root stimulator implant (mean \pm standard error of measurement $=148.6 \mathrm{mmHg} \pm 10.0$ at rest vs $99.78 \mathrm{mmHg} \pm 6.7$ during FES). ${ }^{*}$ Significant at $p=0.002$.

studied forward-leaning and dynamic wheelchair cushion/tilt but were greater than those obtained by Levine et al. who studied gluteal-muscle stimulation [24]. One possible explanation for these discrepant results is that the S2 nerve root stimulation in our study efficiently activates the entire neuromuscular bundle. In contrast, surface FES of the gluteus maximus only activates certain regions of muscle fibers. As one might expect, the gluteus maximus is difficult to stimulate by surface electrodes because it has greater mass and covers adipose tissue.

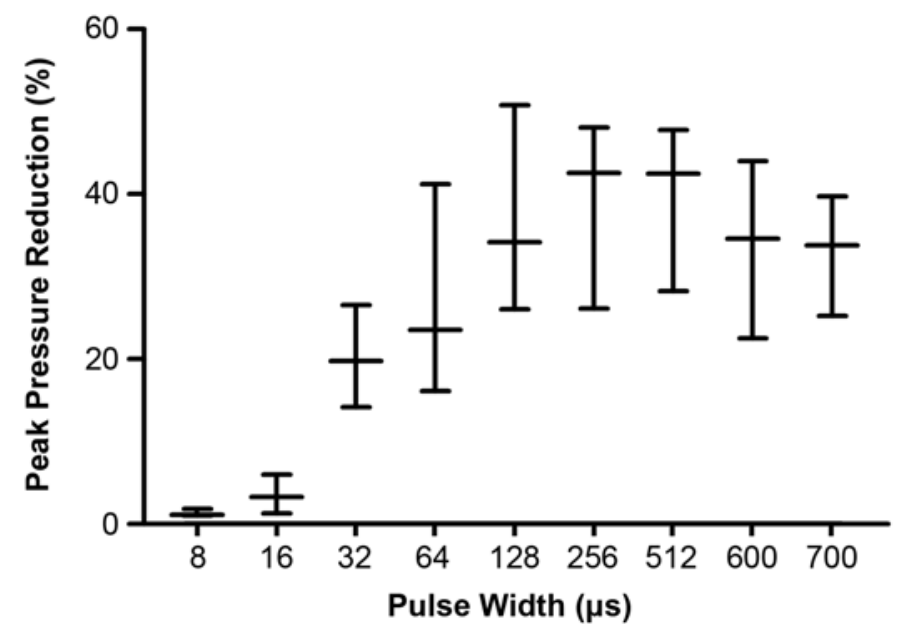

Figure 6.

Percentage reduction of ischial tuberosity peak pressure at different functional electrical stimulation pulse widths in five participants with spinal cord injury and sacral anterior root stimulator implant.

After SCI, an individual's loss of motor control and consequent immobility lead to disuse and atrophy of the gluteal muscles, which increases interface pressures under the ITs during sitting. In our study, baseline peak pressures under the ITs during sitting were higher in the SCI group than the nondisabled group. We found that, with optimal stimulation, peak pressure was reduced 33 percent in the five participants with SCI and nearly 20 percent in the five nondisabled participants. Less pressure reduction in the nondisabled participants is attributable, in part, to a relatively lower level and duration of stimulation compared with the FES applied via SARS 
implant in the participants with SCI. Otherwise, this difference in pressure reduction may reflect variations in individual body weight and pelvic anatomy or our small sample sizes. Nevertheless, these results suggest that FES applied via SARS implant may be most beneficial for patients already experiencing atrophied gluteal muscles.

While PU development is undoubtedly multifactorial, prolonged pressure loading that exceeds the tissue's tolerance is a major factor in ulcer development. Brienza et al. evaluated the relationship between PU incidence and buttock-seat cushion interface pressure in at-risk elderly persons who used wheelchairs [37]. They found that higher interface pressure measurements were associated with a higher incidence of sitting-acquired PUs. Similarly, Conine et al. studied the effectiveness of Jay cushions in PU prevention in 163 elderly persons who used wheelchairs [38]. They found that the incidence of PUs was significantly higher among those persons with high peak pressures of $60 \mathrm{mmHg}$ or higher. Therefore, a sensible approach to ischial PU prevention is the reduction of pressures under the ITs and the redistribution of seat interface pressure.

In this pilot study, we looked mainly at the acute effects of sacral nerve root stimulation on pressure changes. FMS is a noninvasive technique for assessment of whether sacral nerve root stimulation efficiently induces gluteal muscle contractions and thereby reduces sitting pressure. In our study, we optimized the stimulation parameters (either through SARS implant or FMS) to achieve a force of gluteal muscle contraction sufficient to measurably affect pressure reduction. Although the pressure changes recorded in this study were statistically significant, application in a clinical setting is a more complex issue. Levine et al. investigated the effect of surface FES on seating pressure for different interface conditions in nondisabled subjects [24]. They found that pressure changes decreased as seating became more compliant. Further studies for determination of the differences in pressure relief achieved by sacral nerve root stimulation are essential. Our center is currently investigating ischial blood perfusion during stimulation [39]. Chronic stimulation of gluteal muscles is postulated to increase blood perfusion $[10,40]$ and produce increased bulk of atrophied muscle, which in turn can improve load distribution at the buttockseat cushion interface [26,41-43]. We are also investigating the effect of chronic S2 nerve root stimulation via SARS implant on tissue loading and hemodynamics.

\section{CONCLUSIONS}

SARS implant is a well-established procedure for bladder and/or bowel management in people with SCI. Although implants have potential risks, the SARS implant has advantages for bladder management, including improved bladder capacity, no hyperreflexia, and reduced urinary tract infection rates [44-47]. Previous studies indicated that the highest detrusor response registered at the S3 and S4 nerves but that the S2 nerves play a subordinate role with regard to the urinary bladder [4849]. Thus far, the electrodes have usually been bilaterally implanted into S3 and S4 nerve roots; S2 is not selected for every patient. We propose that, in addition to restoration of bladder control with a SARS implant, implanted S2 nerve root electrodes may also provide frequent, convenient, and sufficient stimulation of gluteal muscles.

If chronic stimulation of S2 nerve roots can increase muscle bulk, redistribute seating pressure, and improve local vascular circulation, then an implanted S2 nerveroot stimulator may become an alternative method of ischial PU prevention in people with SCI.

\section{ACKNOWLEDGMENTS}

We would like to thank Mr. John Bycroft for helping recruit patients and Professor Satsue Hagisawa and Rachel Brown for their assistance and advice during various parts of this study.

This material was the result of work supported by the Royal National Orthopaedic Hospital, Stanmore, United Kingdom, grant 03/010. This work was also supported by the Association for Spinal Injury Research, Rehabilitation, and Reintegration, Stanmore, United Kingdom.

The authors have declared that no conflicting interests exist.

\section{REFERENCES}

1. Krause JS, Vines CL, Farley TL, Sniezek J, Coker J. An exploratory study of pressure ulcers after spinal cord injury: relationship to protective behaviors and risk factors. Arch Phys Med Rehabil. 2001;82(1):107-13. [PMID: 11239295]

2. Bennett G, Dealey C, Posnett J. The cost of pressure ulcers in the UK. Age Ageing. 2004;33(3):230-35. [PMID: 15082426]

3. Tam EW, Mak AF, Lam WN, Evans JH, Chow YY. Pelvic movement and interface pressure distribution during 
manual wheelchair propulsion. Arch Phys Med Rehabil. 2003; 84(10):1466-72. [PMID: 14586913]

4. Byrne DW, Salzberg CA. Major risk factors for pressure ulcers in the spinal cord disabled: a literature review. Spinal Cord. 1996;34(5):255-63. [PMID: 8963971]

5. Ash D. An exploration of the occurrence of pressure ulcers in a British spinal injuries unit. J Clin Nurs. 2002;11(4): 470-78. [PMID: 12100643]

6. Mawson AR, Siddiqui FH, Connolly BJ, Sharp CJ, Summer WR, Biundo JJ Jr. Sacral transcutaneous oxygen tension levels in the spinal cord injures: risk factors for pressure ulcers? Arch Phys Med Rehabil. 1993;74(7):745-51. [PMID: 8328898]

7. Zacharkow D. Wheelchair posture and pressure sores. Springfield (IL): Charles C. Thomas Publishing; 1984.

8. Stinson MD, Porter-Armstrong A, Eakin P. Seat-interface pressure: pilot study of the relationship to gender, body mass index, and seating position. Arch Phys Med Rehabil. 2003;84(3):405-9. [PMID: 12638109]

9. Mawson AR, Biundo JJ Jr, Neville P, Linares HA, Winchester Y, Lopez A. Risk factors for early occurring pressure ulcers following spinal cord injury. Am J Phys Med Rehabil. 1988;67(3):123-27. [PMID: 3377890]

10. Bogie KM, Triolo RJ. Effects of regular use of neuromuscular electrical stimulation on tissue health. J Rehabil Res Dev. 2003;40(6):469-76. [PMID: 15077659]

11. Ragnarsson KT. Physiologic effects of functional electrical stimulation-induced exercises in spinal cord-injured individuals. Clin Orthop Rel Res. 1988;(233):53-63. [PMID: 3261220$]$

12. Krouskop TA, Noble PC, Garber SL, Spencer WA. The effectiveness of preventive management in reducing the occurrence of pressure sores. J Rehabil Res Dev. 1983; 20(1):74-83. [PMID: 6887068]

13. Niazi ZB, Salzberg CA, Byrne DW, Viehbeck M. Recurrence of initial pressure ulcer in persons with spinal cord injuries. Adv Wound Care. 1997;10(3):38-42. [PMID: 9306777]

14. Garber SL, Rintala DH. Pressure ulcers in veterans with spinal cord injury: a retrospective study. J Rehabil Res Dev. 2003;40(5):433-41. [PMID: 15080228]

15. Krause JS, Broderick L. Patterns of recurrent pressure ulcers after spinal cord injury: identification of risk and protective factors 5 or more years after onset. Arch Phys Med Rehabil. 2004;85(8):1257-64. [PMID: 15295750]

16. Bogie KM, Nuseibeh I, Bader DL. Early progressive changes in tissue viability in the seated spinal cord injured subject. Paraplegia. 1995;33(3):141-47. [PMID: 7784116]

17. Guttmann L. Spinal cord injuries: comprehensive management and research. 2nd ed. London (England): J.B. Lippincott; 1976. p. 244.

18. Ferguson-Pell MW, Wilkie IC, Reswick JB, Barbenel JC. Pressure sore prevention for the wheelchair-bound spinal injury patient. Paraplegia. 1980;18(1):42-51. [PMID: 7375126]

19. Coggrave MJ, Rose LS. A specialist seating assessment clinic: changing pressure relief practice. Spinal Cord. 2003; 41(12):692-95. [PMID: 14639449]

20. Sachse RE, Fink SA, Klitzman B. Comparison of supine and lateral positioning on various clinically used support surfaces. Ann Plast Surg. 1998;41(5):513-18. [PMID: 9827955]

21. Bain D, Ferguson-Pell MW, McLeod A. Evaluation of mattresses using interface pressure mapping. J Wound Care. 2003;12(6):231-35. [PMID: 12838601]

22. Yarkony GM, Heinemnn W. Pressure ulcers. In: Stover SL, DeLisa JA, Whiteneck GG, editors. Spinal cord injury: clinical outcomes from the model systems. Gaithersburg (MD): Aspen Publishers; 1995. p. 100-119.

23. Levine SP, Kett RL, Cederna PS, Brooks SV. Electric muscle stimulation for pressure sore prevention: tissue shape variation. Arch Phys Med Rehabil. 1990;71(3):210-15. [PMID: 2180391]

24. Levine SP, Kett RL, Cederna PS, Bowers LD, Brooks SV. Electrical muscle stimulation for pressure variation at the seating interface. J Rehabil Res Dev. 1989;26(4):1-8. [PMID: 2600864]

25. Levine SP, Kett RL, Ferguson-Pell MW. Tissue shape and deformation versus pressure as a characterization of the seating interface. Assist Technol. 1990;2(3):93-99.

26. Bogie KM, Reger SI, Levine SP, Sahgal V. Electrical stimulation for pressure sore prevention and wound healing. Assist Technol. 2000;12(1):50-66. [PMID: 11067577]

27. Lippert-Gruner M. Gluteal neuromuscular stimulation in therapy and prophylaxis of recurrent sacral pressure ulcers. Spinal Cord. 2003;41(6):365-66. [PMID: 12746744]

28. Sheriff MK, Shah PJ, Fowler C, Mundy AR, Craggs MD. Neuromodulation of detrusor hyper-reflexia by functional magnetic stimulation of sacral roots. Br J Urol. 1996;78(1): 39-46. [PMID: 8795398]

29. Paus T, Jech R, Thompson CJ, Comeau R, Peters T, Evans AC. Transcranial magnetic stimulation during positron emission tomography: a new method for studying connectivity of the human cerebral cortex. J Neurosci. 1997;17(9): 3178-84. [PMID: 9096152]

30. Siekman AS, Axelson P, Noon JH. Design of a test fixture for wheelchair cushion testing. In: Proceedings of the RESNA 1998 Annual Conference; 1998 Jun 26-30; Minneapolis, Minnesota. Arlington (VA): RESNA Press; 1998. p. 113-15.

31. Staarink HAM. Sitting posture, comfort and pressure. Delft (the Netherlands): Delft University Press; 1995.

32. Brindley GS, Polkey CE, Rushton DN. Sacral anterior root stimulators for bladder control in paraplegia. Paraplegia. 1982;20(6):365-81. [PMID: 6984503] 
33. Kirkham AP, Knight SL, Craggs MD, Casey AT, Shah PJ. Neuromodulation through sacral nerve roots 2 to 4 with a Finetech-Brindley sacral posterior and anterior root stimulator. Spinal Cord. 2002;40(6):272-81. [PMID: 12037708$]$

34. Ferguson AC, Keating JF, Delargy MA, Andrews BJ. Reduction of seating pressure using FES in patients with spinal cord injury. A preliminary report. Paraplegia. 1992; 30(7):474-78. [PMID: 1508561]

35. Burns SP, Betz KL. Seating pressures with conventional and dynamic wheelchair cushions in tetraplegia. Arch Phys Med Rehabil. 1999;80(5):566-71. [PMID: 10326923]

36. Henderson JL, Price SH, Brandstater ME, Mandac BR. Efficacy of three measures to relieve pressure in seated persons with spinal cord injury. Arch Phys Med Rehabil. 1994;75(5):535-39. [PMID: 8185445]

37. Brienza DM, Karg PE, Geyer MJ, Kelsey S, Trefler E. The relationship between pressure ulcer incidence and buttockseat cushion interface pressure in at-risk elderly wheelchair users. Arch Phys Med Rehabil. 2001;82(4):529-33. [PMID: 11295017$]$

38. Conine TA, Hershler C, Daechsel D, Peel C, Pearson A. Pressure sore prophylaxis in elderly patients using polyurethane foam or Jay wheelchair cushions. Int J Rehabil Res. 1994;17(2):123-37. [PMID: 7960335]

39. Liu LQ, Craggs MD, Nicholson GP, Knight SL, Chelvarajah R, Gall A, Middleton FRI, Ferguson-Pell M. Interface pressure and cutaneous blood perfusion changes under the ischial tuberosities during sacral nerve root stimulation. In: Proceedings of the International Conference on Posture and Wheeled Mobility; 2005 Apr 11-15; Exeter, United Kingdom. Exeter (United Kingdom): Posture and Mobility Group; 2005.

40. Salmons S, Henriksson J. The adaptive response of skeletal muscle to increase use. Muscle Nerve. 1981;4(2):94-105. [PMID: 7010156]
41. Garber SL, Krouskop TA. Body build and its relationship to pressure distribution in the seated wheelchair patient. Arch Phys Med Rehabil. 1982;63(1):17-20. [PMID: 7055413]

42. Baldi JC, Jackson RD, Moraille R, Mysiw WJ. Muscle atrophy is prevented in patients with acute spinal cord injury using functional electrical stimulation. Spinal Cord. 1998;36(7):463-69. [PMID: 9670381]

43. Creasey GH, Ho CH, Triolo RJ, Gater DR, DiMarco AF, Bogie KM, Keith MW. Clinical applications of electrical stimulation after spinal cord injury. J Spinal Cord Med. 2004;27(4):365-75. [PMID: 15484667]

44. Brindley GS. The first 500 patients with sacral anterior root stimulator implants: general description. Paraplegia. 1994; 32(12):795-805. [PMID: 7708419]

45. Brindley GS, Rushton DN. Long-term follow-up of patients with sacral anterior root stimulator implants. Paraplegia. 1990;28(8):469-75. [PMID: 2263403]

46. Creasey GH. Electrical stimulation of sacral roots for micturition after spinal cord injury. Urol Clin North Am. 1993; 20(3):505-15. [PMID: 8351775]

47. Koldewijn EL, Van Kerrebroeck PE, Rosier PF, Wijkstra H, Debruyne FM. Bladder compliance after posterior sacral root rhizotomies and anterior sacral root stimulation. J Urol. 1994;151(4):955-60. [PMID: 8126835]

48. Schmidt RA, Bruschini H, Van Gool J, Tanagho EA. Micturition and the male genitourinary response to sacral root stimulation. Invest Urol. 1979;17(2):125-29. [PMID: 313925]

49. Tanagho EA, Schmidt RA, Orvis BR. Neural stimulation for control of voiding dysfunction: a preliminary report in 22 patients with serious neuropathic voiding disorders. J Urol. 1989;142(2 pt 1):340-45. [PMID: 2787411]

Submitted for publication August 8, 2005. Accepted in revised form February 23, 2006. 